\title{
Impact of Hepatitis C Virus Infection on the in-Hospital Mortality of Patients with Alcoholic Hepatitis
}

\author{
AK Singal ${ }^{1}$, BS Anand ${ }^{2}$ and YF Kuo ${ }^{3}$ \\ ${ }^{1}$ Department of Internal Medicine, Division of Gastroenterology, and Department of Biostatistics, \\ Center for Aging University of Texas Medical Branch; Galveston; TX \\ ${ }^{2}$ Department of Gastroenterology and Hepatology, Michael DeBakey VA Medical Center, Baylor \\ College of Medicine, Houston, TX \\ ${ }^{3}$ Department of Biostatistics, Center for Aging, University of Texas Medical Branch; Galveston; TX
}

\begin{abstract}
Background and Aim: There is limited data on the impact of hepatitis $\mathrm{C}$ virus (HCV) infection on alcoholic hepatitis $(\mathrm{AH})$. The present study was performed to assess the effect of HCV on inhospital mortality of AH. Methods: Using Nationwide Inpatient Sample (1998-2007), AH admissions were stratified based on the presence or absence of HCV. Results: Of 111,726 AH admissions, 7,240 (6.5\%) were HCV +ve. These patients were different from HCV -ve subjects in age, race, Charlston Comorbidity index, pay source, hospital characteristics, complications, and interventions needed. In-hospital mortality from AH was higher in presence of HCV $(3.8 \%$ vs. 3.1\%; $\mathrm{P}=0.001)$. On multivariate logistic regression, $\mathrm{HCV}$ infection independently predicted in-hospital mortality of $\mathrm{AH}$ after controlling for other variables including calendar year [OR 1.29 (CI: 1.12-1.49; $\mathrm{P}=0.0005$ )]. Other strong predictors were hepatic encephalopathy and renal failure. Conclusion: Concomitant HCV infection is an important risk factor for in-hospital mortality in AH. Further studies with longer follow up are needed to assess the impact of HCV on $\mathrm{AH}$ patients at 6 months and at one year.
\end{abstract}

Keywords: Alcoholic hepatitis; In-hospital mortality; Hepatitis C; HCV; National inpatient sample.

\section{Introduction}

Hepatitis C virus (HCV) infection and alcohol are the two most common causes of liver disease in the United States (US) (Anonymous 2002). It is well established that alcoholics with HCV infection develop cirrhosis and hepatocellular carcinoma more frequently than alcoholics without HCV infection (Peters and Terrault 2002; A. K. Singal and Anand, 2007). However, there is limited data on the effect of CHC on the outcome of alcoholic hepatitis (AH). We conducted the present study using the
National Inpatient Sample (NIS) dataset to examine the impact of HCV on the inhospital mortality in patients with $\mathrm{AH}$. The study was approved by the Institutional review board.

\section{Methods}

The Nationwide Inpatient Sample (NIS) dataset with details of about 8 million hospital discharges (with up to 15 diagnosis and 15 procedure codes) from over 1,050 hospitals in 42 states in the US. Discharges with a primary or secondary

Copyright (C) 2012 AK Singal, BS Anand and YF Kuo. This is an open access article distributed under the Creative Commons Attribution License unported 3.0, which permits unrestricted use, distribution, and reproduction in any medium, provided that original work is properly cited. Contact author: AK Singal, Email: ashwanisingal.com@gmail.com 
diagnosis of AH (ICD-9-CM code 571.1) were stratified based on their HCV status (ICD-9-CM code 070.41, 070.44, 070.51, $070.54,070.70,070.71)$. The primary outcome measure was in-hospital mortality. Two groups of AH patients (HCV +ve and HCV -ve) were compared with respect to patient demographics, Charlston Comorbidity Index (CCI) (Quan et al. 2005), admission type (elective vs. emergency), pay source (self employed or medicaid payment), hospital characteristics (urban or rural, teaching or non-teaching, bed size and geographical location), length of hospital stay, liver disease complications, diagnostic or therapeutic interventions, and outcome. Specific codes were used to identify each of these variables in the dataset (Table 1).

Table 1. List of International Classification of Diseases (ICD-09) Codes Used for the Analysis

\begin{tabular}{|c|c|}
\hline 571.1 & \begin{tabular}{|l} 
Alcoholic hepatitis \\
\end{tabular} \\
\hline 571.2 and $\mathbf{5 7 1 . 5}$ & Alcoholic cirrhosis and unspecified cirrhosis \\
\hline 070.2070 .3 & Hepatitis B \\
\hline 275.0 & Hereditary hemochromatosis \\
\hline 965.0 & Tylenol overdose \\
\hline 453 and 452 & Budd Chiari syndrome and Portal vein thrombosis \\
\hline 571.42 & Auto immune hepatitis \\
\hline 155.0 & Hepatocellular carcinoma \\
\hline $070.41,070.51 ; 070.44,070.54 ; 070.70,070.71$ & Acute HCV; chronic HCV; unspecified HCV \\
\hline $456.0,456.20$ & Esophageal varices with bleeding \\
\hline $\mathbf{7 8 9 . 5}$ & Ascites \\
\hline 567.23 & Spontaneous bacterial peritonitis \\
\hline 572.2 & Hepatic encephalopathy \\
\hline $572.4,584.9$, and 584.5 & Hepatorenal syndrome, AKI, and ATN \\
\hline $50.11,50.12,50.13,50.19$ & $\begin{array}{c}\text { Liver biopsy (Closed), open wedge, transjugular, } \\
\text { laparoscopic }\end{array}$ \\
\hline 39.1 & TIPS \\
\hline $42.23,42.33,44.13,45.13$ & Endoscopic control of bleeding \\
\hline $99.03,99.04,99.05,99.06$ & Transfusion of blood and blood products \\
\hline 99.15 & Nutritional supplementation \\
\hline 54.91 & Large volume paracentesis \\
\hline $39.95,54.98$ & Hemodialysis, peritoneal dialysis \\
\hline $96.7,96.04,96.05$ & Mechanical ventilation, endotracheal intubation \\
\hline
\end{tabular}

Continuous variables were compared using t-test and categorical variables using Chisquare test. Logistic regression model was built to study the independent association of HCV and in-hospital mortality. Variables which could have confounded the outcome were entered into the model. The results of logistic regression were described as odds ratio (OR) with 95\% confidence interval $(95 \% \mathrm{CI})$.

\section{Results}

A total of $111,726 \mathrm{AH}$ admissions $(6.5 \%$ with concomitant HCV infection) between 1998 and 2007 were analyzed. Patients with $\mathrm{AH}$ and concomitant HCV infection were younger, required admission on an emergent basis, were of black or Hispanic ethnicity, had a higher CCI score, were on Medicaid pay source, were more likely to be in a large, urban teaching hospital, located in the Western region of the country, and more frequently had liver related complications (Table 2 ). 
Table 2. Characteristics of Patients with Alcoholic Hepatitis (1998-2007): Comparison of HCV Positive and HCV Negative Cases

\begin{tabular}{|c|c|c|c|c|c|c|c|}
\hline \multicolumn{4}{|c|}{ Patient characteristics } & \multicolumn{4}{|c|}{ Hospital characteristics } \\
\hline & $\begin{array}{c}\text { HCV +ve } \\
(\mathrm{N}=7,240)\end{array}$ & $\begin{array}{c}\text { HCV -ve } \\
(\mathrm{N}=104,486)\end{array}$ & & & $\begin{array}{c}\text { HCV +ve } \\
(\mathrm{N}=7,240)\end{array}$ & $\begin{array}{c}\text { HCV -ve } \\
(\mathrm{N}=104,486)\end{array}$ & \\
\hline & $N(\%)$ & $N(\%)$ & & & $N(\%)$ & $N(\%)$ & \\
\hline Age in yrs & & & & Hospital Control & & & \\
\hline$<40$ & $1246(17)$ & $24,610(24)$ & & Govt. or Pvt. & $3789(63)$ & $51,945(59)$ & \\
\hline $40-50$ & $3544(49)$ & $37,040(35)$ & $<0.0001$ & Govt. Non federal & $437(7)$ & $7254(8)$ & \\
\hline $50-60$ & $2129(29)$ & $26,840(26)$ & & Pvt. Non profit & $1047(16)$ & $17,038(19)$ & $<0.0001$ \\
\hline$>60$ & $321(5)$ & $15,996(15)$ & & Pvt. invest own & $476(8)$ & $8500(10)$ & \\
\hline Males & $5181(72)$ & $74,468(71)$ & 0.79 & $P v t$ & $241(6)$ & $3904(4)$ & \\
\hline Ethnicity & & & & Urban hospital & $5271(88)$ & $75,452(85)$ & $<0.0001$ \\
\hline Caucasian & $3837(53)$ & $54,905(53)$ & & $\begin{array}{l}\text { Teaching } \\
\text { hospital }\end{array}$ & $2983(50)$ & $35,889(41)$ & $<0.0001$ \\
\hline$A A$ & $959(13)$ & $11,337(11)$ & $<0.0001$ & Hospital region & & & \\
\hline Hispanic & $641(9)$ & $8029(8)$ & & North-east & $1166(19)$ & $17,059(19)$ & \\
\hline Others & $1803(25)$ & $30,215(29)$ & & Mid-west & $1160(19)$ & $20,973(22)$ & $<0.0001$ \\
\hline Elective admissions & $353(6.7)$ & $5164(7.7)$ & 0.0007 & South & 2145 (37) & $32,362(37)$ & \\
\hline $\begin{array}{l}\text { Charlson comorbidity } \\
\text { index (Mean } \pm S D)\end{array}$ & $0.38 \pm 0.73$ & $0.32 \pm 0.64$ & $<0.0001$ & West & $1519(25)$ & $18,323(21)$ & \\
\hline Pay Source & & & & $\begin{array}{c}\text { Hospital Bed } \\
\text { size } \\
\end{array}$ & & & \\
\hline Medicare & $1117(15)$ & $17,754(17)$ & & Small & $759(13)$ & $12,414(14)$ & \\
\hline Medicaid & $2337(32)$ & $19,619(19)$ & $<0.0001$ & Medium & $1769(29)$ & $25,674(29)$ & 0.0015 \\
\hline Private and self-pay & $3017(42)$ & $57,938(56)$ & & Large & $3462(58)$ & $50,553(57)$ & \\
\hline No charge & $748(10)$ & $8838(8)$ & & & & & \\
\hline \multicolumn{8}{|l|}{$\begin{array}{c}\text { Complications of liver } \\
\text { disease }\end{array}$} \\
\hline Variceal bleeding & $185(2.6)$ & $1102(1.1)$ & $<0.0001$ & & & & \\
\hline Ascites & $1093(15)$ & $10,073(10)$ & $<0.0001$ & & & & \\
\hline$S B P$ & $37(0.51)$ & $188(0.18)$ & $<0.0001$ & & & & \\
\hline $\begin{array}{c}\text { Hepatic } \\
\text { encephalopathy }\end{array}$ & $681(9.4)$ & $7011(6.7)$ & $<0.0001$ & & & & \\
\hline $\begin{array}{c}\text { Acute renal } \\
\text { insufficiency and HRS }\end{array}$ & $405(5.6)$ & $4953(4.7)$ & 0.001 & & & & \\
\hline \multicolumn{8}{|l|}{$\begin{array}{c}\text { Diagnostic or } \\
\text { therapeutic } \\
\text { interventions }\end{array}$} \\
\hline$E V L$ & $1(0.01)$ & $11(0.01)$ & 0.79 & & & & \\
\hline Blood Transfusion & $742(10)$ & $7826(7.5)$ & $<0.0001$ & & & & \\
\hline $\begin{array}{c}\text { Nutritional } \\
\text { supplementation }\end{array}$ & $63(0.9)$ & $1093(1.04)$ & 0.15 & & & & \\
\hline LVP & $613(8.5)$ & $5456(5.2)$ & $<0.0001$ & & & & \\
\hline Dialysis & $60(0.83)$ & $818(0.78)$ & 0.67 & & & & \\
\hline
\end{tabular}

HCV: Hepatitis C virus; AA: African Americans; SBP: Spontaneous bacterial peritonitis; TIPS: Transjugular intrahepatic portosystemic shunt; EVL: Endoscopic variceal ligation; LVP: Large volume paracenteses; HRS: Hepatorenal syndrome

Although, overall mean length of hospital stay was similar between HCV positive and HCV negative groups $(6.0 \pm 5.8$ vs. $5.5 \pm 39$ days; $\mathrm{P}=0.28)$, the proportion of patients staying in the hospital for more than 7 days was higher in HCV +ve AH admissions (23\% vs. 21\%; P<0.0001).

A total of 3,541 (3.2\%) patients died (higher with HCV: 3.8\% vs. 3.1\%; $\mathrm{P}=0.001$ ) during the hospital stay. In-hospital mortality decreased at about 7\% per year [OR 0.93 (CI: 0.91-0.94; $\mathrm{P}<0.0001)]$ over the last decade. After controlling for other confounding variables including the calendar year, HCV was an independent predictor of in-hospital mortality in patients admitted with AH (Table 3). 
Table 3. Logistic Regression Model to Determine Independent Prediction of HCV on the in-Hospital Mortality of Patients with Acute Alcoholic Hepatitis

\begin{tabular}{|c|c|c|c|c|c|c|c|}
\hline & & OR & $95 \% \mathrm{CI}$ & & & OR & $95 \% \mathrm{CI}$ \\
\hline \multicolumn{4}{|c|}{ Patient characteristics } & \multicolumn{4}{|c|}{ Hospital characteristics } \\
\hline HCV & & 1.29 & $1.12-1.49$ & $\begin{array}{l}\text { Hospital } \\
\text { teaching }\end{array}$ & Non-teaching & 1.00 & $1.00-1.00$ \\
\hline & & & & & Teaching & 1.19 & $1.1-1.3$ \\
\hline \multirow[t]{3}{*}{ Calendar Year } & & 0.93 & $0.91-0.94$ & & & & \\
\hline & & & & & North-east & 1.00 & $1.00-1.00$ \\
\hline & $<40$ & 1.00 & $1.00-1.00$ & $\begin{array}{l}\text { Hospital } \\
\text { region }\end{array}$ & Mid-west & 0.93 & $0.82-1.05$ \\
\hline \multirow[t]{4}{*}{ Age in yrs } & $40-50$ & 1.53 & $1.34-1.74$ & & South & 0.91 & $0.82-1.02$ \\
\hline & $50-60$ & 2.12 & $1.86-2.42$ & & West & 1.00 & $0.89-1.13$ \\
\hline & $>60$ & 3.73 & $3.22-4.31$ & & & & \\
\hline & & & & & Small & 1.00 & $1.00-1.00$ \\
\hline \multirow[t]{3}{*}{ Gender } & Male & 1.00 & $1.00-1.00$ & $\begin{array}{l}\text { Hospital Bed } \\
\text { size }\end{array}$ & Medium & 1.19 & $1.04-1.36$ \\
\hline & Female & 1.06 & $0.97-1.15$ & & Large & 1.33 & $1.17-1.50$ \\
\hline & Hispanic & 1.00 & $1.00-1.00$ & $\begin{array}{l}\text { Hospital } \\
\text { Location }\end{array}$ & Rural & 1.00 & $1.00-1.00$ \\
\hline \multirow[t]{3}{*}{ Race } & Caucasian & 1.31 & $1.12-1.53$ & & Urban & 0.91 & $0.81-1.02$ \\
\hline & African American & 1.04 & $0.86-1.27$ & & & & \\
\hline & Others & 1.12 & $0.95-1.33$ & & & & \\
\hline \multirow[t]{2}{*}{ CCI } & & 1.26 & $1.20-1.32$ & & & & \\
\hline & Medicare & 1.00 & $1.00-1.00$ & & & & \\
\hline \multirow[t]{4}{*}{ Pay source } & Medicaid & 1.19 & $1.04-1.35$ & & & & \\
\hline & Private and self-pay & 0.97 & $0.87-1.09$ & & & & \\
\hline & No charge & 1.15 & $1.00-1.35$ & & & & \\
\hline & Variceal Bleeding & 2.24 & $1.82-2.76$ & & & & \\
\hline \multirow[t]{3}{*}{ Complications } & Encephalopathy & 6.6 & $6-7.2$ & & & & \\
\hline & $\begin{array}{c}\text { Acute renal } \\
\text { insufficiency and } \\
\text { HRS } \\
\end{array}$ & 13.3 & $12.2-14.6$ & & & & \\
\hline & TIPS & 1.18 & $0.55-2.52$ & & & & \\
\hline \multirow[t]{2}{*}{ Procedures } & Blood transfusion & 2.8 & $2.6-3.1$ & & & & \\
\hline & $\begin{array}{c}\text { Nutritional } \\
\text { supplementation }\end{array}$ & 4.0 & $3.3-4.9$ & & & & \\
\hline
\end{tabular}

OR: Odds ratio; CI: Confidence interval; TIPS: Transjugular intra-hepatic portosystemic shunt; CCI: Charlson comorbidity index; HCV: hepatitis $C$ virus; HRS: Hepatorenal syndrome

Other predictors of in-hospital mortality were age at admission, Caucasian race, Medicaid pay source, CCI score, admission in a teaching hospital, complications from liver disease (renal failure, hepatic encephalopathy, and variceal bleeding), 
and the need for diagnostic or therapeutic interventions.

\section{Discussion}

Although, AH is an acute condition, concomitant cirrhosis may be present in many patients (O'Shea et al.). The clinical presentation of worsening cirrhosis may mimic $\mathrm{AH}$ if the clinical or laboratory evidence of systemic inflammation such as fever, chills, tender hepatomegaly and neutrophilic leucocytosis are lacking. Therefore, we excluded admissions from the study population with a primary diagnosis of cirrhosis.

Patients with $\mathrm{AH}$ and concomitant $\mathrm{HCV}$ infection had worse outcome with a higher in-hospital mortality. This is reflected with higher rate of complications amongst patients with concomitant HCV infection. Several studies in the past have assessed the impact of HCV on alcoholic cirrhosis. However, the effect of HCV on the outcome of $\mathrm{AH}$ has not been examined properly. A previous study observed that patients with $\mathrm{AH}$ had a worse outcome at 6 months follow-up in the presence of HCV infection compared to patients without HCV (A. S. Singal, S; Kuo, YF; Weinman, SA. 2011). However, this was a small retrospective study from a single institution.

$\mathrm{AH}$ is a serious medical condition with a mortality of about $40 \%$ at 6 months in patients with severe disease despite treatment with corticosteroids and/or pentoxifylline (Lucey et al. 2009). In the present study, the overall in-hospital mortality was only $3.2 \%$. Being a data set analysis, rigorous clinical criteria for the diagnosis of $\mathrm{AH}$ can't be applied. It is possible that this may have resulted in a more heterogeneous data collection and included patients with relatively milder forms of disease. The lack of availability of laboratory parameters in this data set limits determination of disease severity. However, we believe that the large sample size from a nationally representative database should overcome this limitation to a great extent. Since the number of admissions was the denominator for estimating the mortality, this may also have falsely lowered the inpatient mortality from $\mathrm{AH}$ as a patient may have been admitted several times prior to mortality. Furthermore, the lack of follow-up data after discharge from the hospital, limits the long-term outcome analysis of these patients.

In summary, our study indicates that inhospital mortality of patients admitted with $\mathrm{AH}$ is low. However, the presence of concomitant HCV infection is associated with higher in-hospital mortality. If these findings are confirmed in prospective studies and from databases with outpatient follow up, HCV infection in patients admitted with AH may be incorporated into scoring systems designed for the assessment of disease severity and mortality.

\section{References}

Anonymous (2002). "National Institutes of Health Consensus Development Conference Statement Management of Hepatitis C: 2002-June 10-12, 2002," Hepatology, 36 (Suppl 5), S3-S20.

Lucey, M. R., Mathurin, P. \& Morgan, T. R. (2009). "Alcoholic Hepatitis," N Engl J Med, 360 (26), 2758-69.

O'Shea, R. S., Dasarathy, S. \& McCullough, A. J. (2010). "Alcoholic Liver Disease," Am J Gastroenterol, 105 (1), 14-32.

Peters, M. G. \& Terrault, N. A. (2002). "Alcohol Use and Hepatitis C," Hepatology, 36 (5 Suppl 1), S220-5.

Quan, H., Sundararajan, V., Halfon, P., Fong, A., Burnand, B., Luthi, J.- C., Saunders, L. D., Beck, C. A., Feasby, T. E. \& Ghali, W. A. (2005). "Coding Algorithms for Defining Comorbidities in ICD-9-CM and ICD-10 Administrative Data," Med Care, 43 (11), 1130-9. 
Singal, A. K. \& Anand, B. S. (2007). "Mechanisms of Synergy between Alcohol and Hepatitis C Virus," J Clin Gastroenterol, 41 (8), 761-72.
Singal, A. K., Sagi, S., Kuo, Y.- F. \& Weinman, S. (2011). "Impact of Hepatitis C on the Outcome and Severity of Acute Alcoholic Hepatitis," Eur J Gastroenterol Hepatol, 23 (3), 204-9. 